\title{
Response to Losanoff JE and Amid PK
}

\author{
Faruk Coskun · M. Mahir Özmen
}

Published online: 17 October 2006

(C) Springer-Verlag 2006

\section{Dear Sir,}

We are pleased to have the interests and also the critiques of Dr. Losanoff and Dr. Amid from Lichtenstein Hernia Institute regarding our technique. Firstly, they claim that the follow-up period was too short to make any firm conclusion on the success of the described technique. Although the technique was being introduced to the surgical environment with that article, this prospective study was planned to evaluate the technique as a result of its being used by us for years and with great success based on the retrospective evaluations, as it was explained in the article [1]. Most of the hernia recurrences first appear at 5 years after surgery, but it usually occurs in the first year after repair [2-4]. As it was explained in the article, our patients were examined at $3,6,9$, and 12 months during the first postoperative year and once per year thereafter at the clinic and underwent complete physical examination. During the first year, only one patient who was in the anterior mesh repair group lost the follow-up, so that the compliance rate was $99.4 \%$. When the article was written, 120 patients were reviewed over 24 months, more than half of them were even over 36 months and only 60 patients were over 12 months. At present, all have completed another

Erratum to: Hernia 9:302-303, DOI 10.1007/s10029-005-0333-y. Unfortunately, the original article was published online with several grave errors, including the order of the authors and the e-mail address. For this reason, the corrected article is given here. The online version of the original article can be found at http://dx.doi.org/10.1007/s10029-005-0333-y.

F. Coskun $(\varangle) \cdot$ M. M. Özmen

Sehit Adem Yavuz Sokak No: 7/11, Kizilay-Ankara, Turkey

e-mail: farukcoskun@mynet.com year with the shortest follow-up being 24 months. We are proud to say that the recurrence rate is still the same. It is not right to say that the phone consultations during this sort of prospective studies are not scientific as the authors have claimed when you are questioning the patients in the course of the phone call and especially if you are examining patients at the clinic as often as we did $[5,6]$. We do accept that the follow-up period is relatively short to make definitive comments on the recurrence rate but it should be accepted as normal considering that the study is describing a new technique. As the study is still continuing, the results obtained might be considered as the preliminary report of an ongoing prospective study.

Secondly, Dr. Losanoff and Dr. Amid claim that Coskun's hernia repair was actually a sort of 'corrupted' Bassini repair. Many new techniques have been introduced since the days when Bassini repair was used with the wide range of acceptance in order to decrease the rate of recurrence. However, only limited number of repairs gained popularity and since then Shouldice is the most commonly used endogen repair technique. One can also give Ponka's and Gillmore's repairs as examples of endogen repairs which have not gained common acceptance. It might not be totally wrong to describe all these techniques as a modification of the original Bassini repair. In this case, the rate of recurrences and all other data based on the technique might be expected to be similar.

If there has to be a resemblance, it is better to resemble the Shouldice repair technique. It is well known that Lichtenstein repair seems better than Shouldice in prospective studies [7,8]. On the other hand, long-term recurrence rate is around $1 \%$ in reports from Shouldice Clinic $[9,10]$. The lower rate of 
recurrence in the reports from specialized hernia clinics supports the common feeling that the surgical experience and best performance of the techniques are the most important parameters. If you consider Shouldice repair as a 'complicated' procedure, you can easily explain the higher rate of recurrence in the studies from the clinics other than the special centers. Hernia repair is the most commonly performed procedure by residents in general surgery. Our study confirms that Coskun's hernia repair is an easily learned and performed technique with great success by surgeons in training which we think is an important advantage in reducing the rate of recurrence.

Thirdly, the relation between hernia and impairment of collagen metabolism is out of the scope of this study. Our aim was not to prove that our technique was better than that of mesh hernioraphy; therefore, we act with ethical responsibility by not performing our technique in any of the cases with recurrences. It is being claimed that prosthetic materials have positive influences on healing in patients with impaired collagen metabolism [11, 12]. On the other hand, microscopic studies on tissue sampling after the mesh repair in those with impaired collagen metabolism revealed that the impairment is still an ongoing problem. When there is no certain predictive marker of impaired collagen metabolism, an effective endogen repair technique in hernia cases apart from recurrences might wipe out the possibility of tissue reaction to an exogenprosthetic material.

Neither Ponkas' nor Gillmores' repair is similar to our technique as Dr. Losanoff and Dr. Amid claim. While fascia transversalis is partly plicated, just only around the internal ring during Ponkas' repair, Gillmore uses nylon darn for the second layer [13, 14].

Lastly, of course we have influences from all previous repairs but none of them was used when this repair was being developed. Our study confirms that Coskuns' repair is as good as Lichtenstein or preperitoneal repairs with the currently available follow-up data.
Once again, we conclude that Coskun's repair is a new technique and of course long-time follow-up data will evaluate its ultimate durability.

\section{References}

1. Coskun F, Ozmen MM, Moran M et al (2005) New technique for inguinal hernia repair. Hernia online first (DOI: 10.1007/ s10029-004-0272-z)

2. Abrahamson J (1998) Etiology and pathophysiology of primary and recurrent groin hernia formation. Surg Clin North Am 78(6):953-972

3. Neumayer L, Gibbie-Hurder A, Jonasson O, Fitzgibbons R et al (2004) Open mesh versus laparoscopic mesh repair of inguinal hernia. New Eng J Med 350(18):1819-1827

4. Nilsson E, Haapaniemi S (1998) Herni registers and specialization. Surg Clin North Am 78(6):1141-1155

5. McGillicuddy JE (1998) Prospective randomized comparison of the Shouldice and Lichtenstein hernia repair procedures. Arch Surg 133:974-978

6. Sondenaa K, Nesvik I, Breivik K, Korner H (2001) Longterm follow up of 1059 consecutive primary and recurrent inguinal hernias in a teaching hospital. Eur J Surg 167:125129

7. Nordin P, Bartelmess P, Jansson C et al (2002) Randomized trial of Lichtenstein versus Shouldice hernia repair in general surgical practice. Br J Surg 89:45-49

8. Danielsson P, Isacson S, Hansen MV (1999) Randomized study of Lichtenstein compared with Shouldice inguinal hernia repair by surgeons in training. Eur J Surg 165:49-53

9. Glassow F (1986) The Shouldice hospital technique. Int Surg 71:148-153

10. Wantz GE (1989) The Canadian repair: personal observations. World J Surg 13:516-521

11. Junge K, Klinge U, Rosch R et al (2004) Decreased collagen typeI/III ratio in patients with recurring hernia after implantation of alloplastic prostheses. Langenbechs Arch Surg 389:17-22

12. Jansen PL, Mertens PR, Klinge U, Schumpelick V (2004) The biology of hernia formation. Surgery 136:1-4

13. Ponka JL (1992) The Ponka approach to the repair of groin hernias. In: Nyhus LM, Baker RJ (eds) Mastery of Surgery, 2nd edn, Vol. 2. Little Brown \& Co, Boston, pp $1566-1583$

14. Fon LJ, Spence RAJ (2000) Sportsman's Hernia. Br J Surg 87(5):545-552 